\title{
28 Resarch Square \\ Quality of life in patients with traumatic brain injury: A single tertiary center experience
}

Muhammad Zafrullah Arifin

Yulius Hermanto ( $\square$ yulius89@kuhp.kyoto-u.ac.jp )

Agung Budi Sutiono

Research

Keywords: EuroQol EQ-5D, traumatic brain injury, quality of life, Hasan Sadikin Hospital

Posted Date: April 30th, 2021

DOI: https://doi.org/10.21203/rs.3.rs-450460/v1

License: (c) (i) This work is licensed under a Creative Commons Attribution 4.0 International License.

Read Full License 


\section{Abstract}

Introduction Traumatic brain injury (TBI) is the main cause of death in motor-vehicle accidents. Investigation on the quality of life in patients with TBI would provide essential information for the society and policy makers in seeking the optimum ways to manage this devastating injury.

Methods A total 178 of patients were involved in this study, consists of 97 patients with TBI and 81 nonTBI patients. The patients' quality of life was evaluated by using Euroqol 5D (EQ-5D) up to 3 months of follow up. Then, the results of EQ-5D were analyzed.

\section{Results}

Impairment in mobility was more profound in patients with TBI compared to non-TBI patients $(23.38 \% \mathrm{vs}$ $9.38 \%, p=0.0414)$. In line with the impaired mobility, impairment of self-care was also more frequently observed in patients with TBI compared to non-TBI patients $(25.97 \%$ vs $12.50 \%, p=0.0459)$. Meanwhile, the other dimensions of EQ-5D were not distinct between patients with TBI and non-TBI patients $(p>$ 0.05). There was a trend of quality of life improvement in patients with TBI during the follow up.

\section{Conclusion}

Patients with TBI are more likely to experience impairment in mobility and self-care compared to non-TBI patients. Hence, TBI potentially affect quality of life.

\section{Introduction}

Traumatic brain injury (TBI) is the main cause of mortality and morbidity in young adults, particularly in motor-vehicle accidents. Several factors such as high mobility and lack of road safety awareness contribute to the high prevalence of TBI in those group. An estimated about more than $50 \%$ of mortality in traffic accidents is due to TBI. Approximately about 50-60 million people suffered from head injuries worldwide annually, with mortality rate of $4 \%$ and morbidity rate of $5 \%{ }^{1,2,3}$

TBI is defined as non-degenerative and non-congenital trauma that occurs as a result of external mechanical force causing head to experience temporary or permanent psychological, cognitive and psychological disorders. ${ }^{4}$ TBI is commonly observed in male than female with ratio of $3: 2 .{ }^{1,2,3}$ The common causes of TBI in adulthood are motor vehicle accidents and violence, while falling is frequent in elderly patients.. ${ }^{5}$ 
Non-TBI patients often have persistent neurological sequelae. Thus, the patient's quality of life is strongly related to the underlying disease, success of the surgery and postoperative rehabilitation. Hence, an appropriate management planning is needed to optimize the quality of life of each patient. ${ }^{6}$

Despite of any complex efforts in the management of patients with TBI, mortality and morbidity among these patients remained high. 7,8 Thus, any information regarding their quality of life after treatment is important as the basic foundation for delivering informed consent for patients and their families. This study aimed to assess the quality of life in patients with TBI after their hospitalization. In order to objectively compare the role of TBI in the prognosis of TBI patients, the results from TBI patients were then compared to the results from non-TBI patients.

\section{Methods}

The ethical clearance was obtained from the Ethical Committee of the Faculty of Medicine, Universitas Padjadjaran and Hasan Sadikin General Hospital. All TBI patients who were $\geq 18$ years old and treated at Hasan Sadikin Hospital in between October 2015 and March 2016 were included in this study. In the nonTBI group, all non-TBI patients who were of the same age group with TBI patients, and treated at the same neurosurgical center in the same period of times were included. Quality of life in both groups were assessed by using Euroqol-5D (EQ-5D) ${ }^{7}$ at the time of discharge and 3 months after being discharged from the hospital. This study was a prospective cohort study, all data were analyzed then described by using tables and graphs. After discharge, the patients were then evaluated by filing in the questionnare at 3 months post hospitalization.

The data was analyzed with Graph Pad Prism 8.0 and $p<0.05$ was considered as statistically significant.

\section{Results}

A total of 178 patients were included in this study, consisting 97 patients with TBI and 81 non-TBI patients. There was no difference in term of social and demographic baseline between two groups (Table $1, p<0.05)$. All patients were evaluated at each time point and 37 patients were died during hospitalization

Twenty patients with TBI and 17 non-TBI patients were died during hospitalization. Patients with TBI who died during hospitalization ( $39.21 \pm 10.39$ years old) tend to be younger than non-TBI patients $(43.87 \pm$ 13.21 years old), however this tendency was not significant $(p=0.2379)$. Majority of mortality occurred in patients with low GCS (3-8) in both groups. Majority of mortality occurred in male, but there was no significant different in both groups (Table 2).

Of the remaining surviving patients (77 patients with TBI and 64 non-TBI patients), were subjected for the evaluation for the quality of life. At 3 months post hospitalization, severe impairment of mobility and selfcare were commonly observed in patients with TBI than patients without TBI ( $p<0.05$, Table 3$)$. There was no difference in term of proportion of patients with severe problem of daily routine activity, pain, and anxiety or depression $(p>0.05)$. 
The patients with TBI had a tendency of improvement in terms of quality of life 3 months after discharged, in all 5 parameters of EQ-5D (mobility, self-care, routine activity, pain, anxiety or depression, $p<0.05)$, however this trend did not reach statistically significant $(p>0.05$, Table 4$)$..

\section{Discussion}

$\mathrm{TBI}$, remains a growing public health concern and represents the major contributor to death and disability globally among all trauma-related injuries and also known as the silent epidemic. ${ }^{1,2,3}$ According to estimates based on literature reported numbers ${ }^{1,2,3}$, about 50-60 million individuals are affected by TBI each year, and it is predicted that close to $50 \%$ of the world's population will sustain a TBI in their lifetime. $^{9}$

Patients with mild, moderate or severe brain injuries suffer from physical, cognitive, behavioural, emotional and social problems, however specific instruments or objective assessment to evaluate quality of life in patients with TBI is scarce. ${ }^{10}$ In Indonesia particularly, the information regarding the quality of life in patients with TBI is severely lacking, hence creating a gap for policy making and public health intervention.

In this study, we investigated the quality of patients with TBI and compared the findings with similar clinical characteristics from non-TBI patients. We found that patients with TBI had a tendency to die at a younger age than non-TBI patients, although it did not reach statistical significance. This finding reflect the condition in our region that majority of patients with TBI were young adults and male. These population are at high risk for having TBI due to highly mobile and lack of road safety awareness. ${ }^{11,12}$

In this study, we found that mortality commonly observed in patients with lower GCS either in patients with TBI and non-TBI. This finding in accordance to literatures, suggesting initial GCS value reflects the state of brain damaged or neurological insults. Low GCS value is associated with dismal prognosis. ${ }^{13,14}$

We found that at 3 months of follow up, patients with TBI were more frequent to have impairment in mobility and self-care than non-TBI patients. This finding indicate that the social burden of TBI might be underestimated. Impairment in mobility and self-care in patients with TBI, particularly in young adults significantly decrease the productivity, hence creating a socioeconomic burden for the society. ${ }^{15}$ Previous study in European community, indicated the quality of life of patients with TBI is better than non-TBI, as indicated by better performance in cognitive function and daily tasks. ${ }^{16}$ On this matter, cultural differences might have influenced the findings, ${ }^{17}$ in our society the attention regarding TBI is severely lacking, hence public awareness of its sequel is low. ${ }^{13,14}$. Nevertheless, there was a trend of quality of life improvement in patients with TBI during the follow-up. Appropriate managed-care could enhance the recovery and promote better quality of life hence reducing socioeconomic burden for the society.

This finding in this study could be used for the reference for the policy making and health care intervention in Indonesia. Further study involving more participants and nationwide would be pivotal to 
confirm the findings in this study.

\section{Conclusions}

There were significant differences in mobility and self-care between patients with TBI and non-TBI patients. Patients with TBI had worse quality of life than non-TBI patients.

\section{Declarations}

\section{Ethics approval and consent to participate}

The ethical clearance was obtained from the Ethical Committee of the Faculty of Medicine, Universitas Padjadjaran and Hasan Sadikin General Hospital.

\section{Consent for publication}

Not applicable

\section{Availability of data and materials}

The datasets used and/or analysed during the current study are available from the corresponding author on reasonable request.

\section{Competing interests}

The authors declare that they have no competing interests.

\section{Funding}

Grants-in-Aid from Indonesia Ministry of Research and Technology (National Research \& Innovation Agency)

\section{Authors` contributions}

All authors met the ICMJE criteria for authorship. MZ and AB contributed to the conception and design. $\mathrm{MZ}$ and $\mathrm{YH}$ performed the statistical analysis and drafting the manuscript. All authors approved the final manuscript.

\section{Acknowledgements}

Not applicable.

\section{Abbreviations}

EQ-5D Euroqol 5D 
GCS Glasgow coma scale

TBI traumatic brain injury

\section{References}

1. Rusnak M. Traumatic brain injury: giving voice to a silent epidemic. Nat Rev Neurol 9:186-187, 2013 209.

2. Rutland-Brown W, Langlois JA, Thomas KE, Xi YL: Incidence of traumatic brain injury in the United States, 2003. J Head Trauma Rehabil 21:544-548, 2006

3. Selassie AW, Cao Y, Church EC, Saunders LL, Krause J: Accelerated death rate in population-based cohort of persons with traumatic brain injury. J Head Trauma Rehabil 29:E8-E19, 2014

4. Ghajar J. Traumatic brain injury. Lancet 2000; 356(9233): 923-929.

5. Mollayeva T, Mollayeva S, Colantonio A. Traumatic brain injury: sex, gender and intersecting vulnerabilities. Nat Rev Neurol 2018; 14: 711-722.

6. Hyder AA, Wunderlich CA, Puvanachandra P, Gururaj G, Kobusingye OC. The impact of traumatic brain injuries: a global perspective. Neuro Rehabil 2007; 22: 341353.

7. Brooks R. EuroQol: the current state of play. Health Policy 1996I 37(1): 53-72.

8. Quaglio G, Galluci M, Brand H, Dawood A, Cobello F. Traumatic brain injury: a priority for public health policy. Lancet Neurol 2017; 16(12): 951-952.

9. Maas AIR, Menon DK, Adelson PD, Andelic N, Bell MJ, Belli A, et al. Traumatic brain injury integrated approaches to improve prevention, clinical care, and research. Lancet Neurol 2017; 16(12): 987-1048.

10. Bullinger M, Azouvi P, Brooks N, Basso A, Christensen A-L, Gobiet W, et al. Quality of life in patients with traumatic brain injury-basic issues, assessment and recommendations. Restor Neurol Neurosci 2002; 20(3-4): 111-124.

11. Faried A, Bachani AM, Sendjaja AN, Hung YW, Arifin MZ. Characteristics of moderate and severe traumatic brain injury of motorcycle crashes in Bandung, Indonesia. World Neurosurg 2017; 100: 195-200.

12. Khairani AF, Azka AN, Faried A, Amelia I, Ardisasmita MN, Tanzilah S, et al. Characteristics of motor vehicle accident patients presenting to a national referral hospital in west java, Indonesia. Southeast Asian J Trop Med Public Health 2018; 49(5): 887-893.

13. Brennan PM, Murray GD, Teasdale GM. Simplifying the use of prognostic information in traumatic brain injury. Part 1: The GCS-Pupil score: an extended index of clinical severity. J Neurosurg 2018; 128: $1612-1620$.

14. Jiang JY, Gao GY, Li WP, Yu MK, Zhu C. Early indicators of prognosis in 846 cases of severe traumatic brain injury. J Neurotrauma 2002; 19(7): 869-874.

15. Puvanachandra P, Hyder AA. The burden of traumatic brain injury in asia: a call for research. Pak J Neurol Sci 2009; 4(1): 27-32. 
16. Geraerds AJLM, Bonsel GJ, Janssen MF, de Jongh MA, Spronk I, Polinder S, Haagsma JA. The added value of the EQ-5D with a cognition dimension in injury patients with and without traumatic brain injury. Quality of Life Research 2019; 28: 1931-1939.

17. Sun S, Chen J, Johannesson M, Kind P, Xu L, Zhang Y, Burstrom K. Population health status in China: EQ-SD results, by age, sex and socioeconomic status, from the National Health Services Survey 2008. Quality of Life Research 2011; 20(3): 309-320.

\section{Tables}

Table 1. Patients' social and demographic characteristics

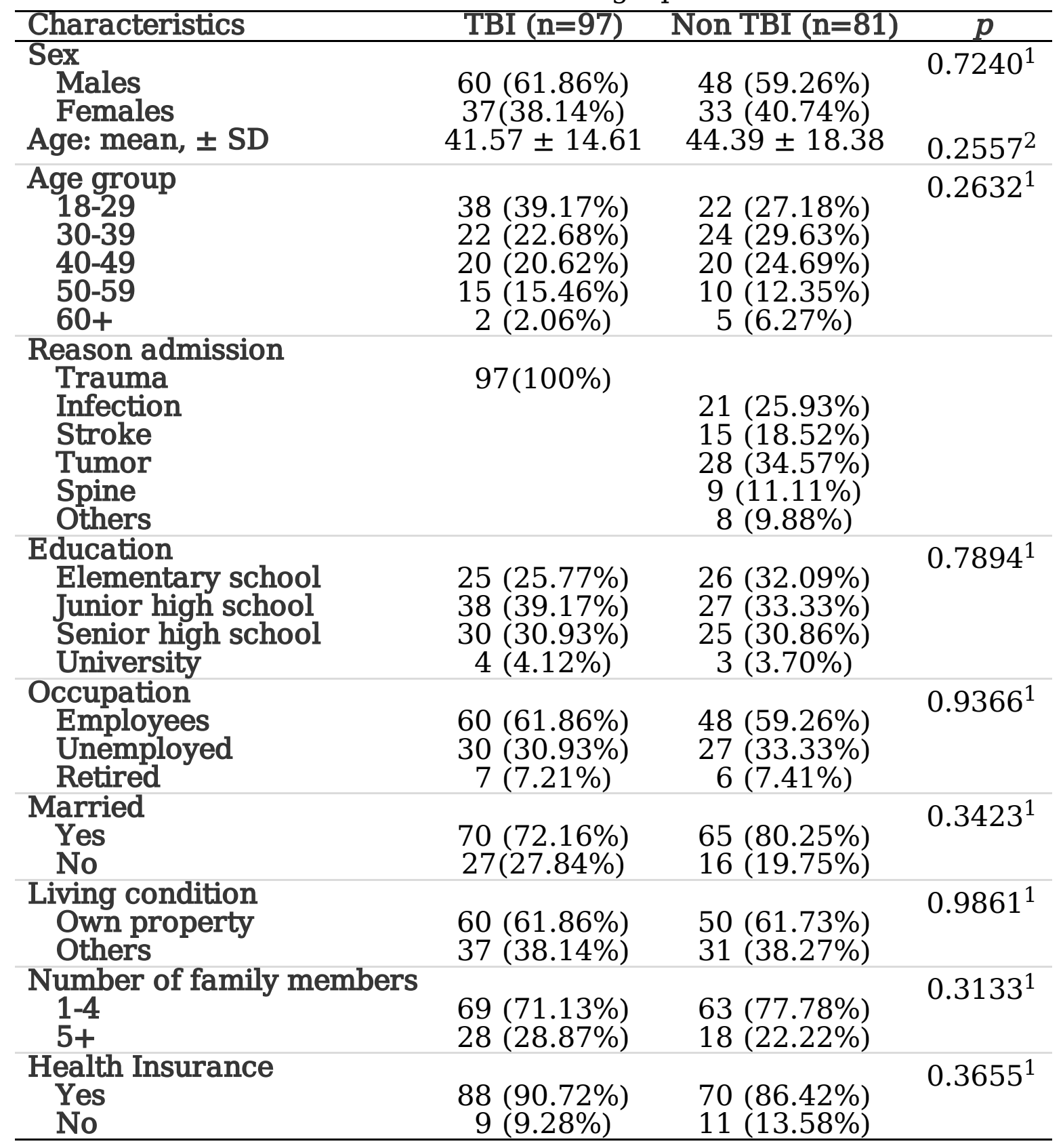

${ }^{1}$ Analyze with chi-square

${ }^{2}$ Analyze with t-test 
Table 2. Characteristics of patients died during hospitalization

\begin{tabular}{lccc}
\hline Characteristics & TBI $(\mathrm{n}=20)$ & Non-TBI $(\mathrm{n}=17)$ & $p$ \\
\hline Age (years) & $39.21 \pm 10.39$ & $43.87 \pm 13.21$ & $0.2379^{1}$ \\
GCS & & & $0.9689^{2}$ \\
3-8 & $14(70.00 \%)$ & $12(70.59 \%)$ & \\
$9-13$ & $6(30.00 \%)$ & $5(29.41 \%)$ & \\
$14-15$ & $0(0.00 \%)$ & $0(0.00 \%)$ & \\
Sex & & & $0.2949^{2}$ \\
Male & $15(75.00 \%)$ & $10(58.82 \%)$ & \\
Female & $5(25.00 \%)$ & $7(41.17 \%)$ & \\
Surgery & & & $0.3193^{2}$ \\
Yes & $12(60.00 \%)$ & $13(76.47 \%)$ & \\
No & $8(40.00 \%)$ & $4(23.53 \%)$ & \\
\hline
\end{tabular}

${ }^{1}$ Analyze with t-test

${ }^{2}$ Analyze with chi-square

Table 3. Evaluation of EQ-5D at 3 months post hospitalization

\begin{tabular}{lccc}
\hline \multicolumn{1}{c}{ Parameter } & TBI (n=77) & Non-TBI (n=64) & $p$ \\
\hline Mobility & & & \\
Severe Impairment & $18(23.38 \%)$ & $6(9.38 \%)$ & $0.0414^{*}$ \\
Non Severe & $59(76.62 \%)$ & $58(90.62 \%)$ & \\
\hline Self-Care & & & \\
\hline$\quad$ Severe Problem & $20(25.97 \%)$ & $8(12.50 \%)$ & $0.0459^{*}$ \\
$\quad$ Non Severe & $57(74.03 \%)$ & $56(87.50 \%)$ & \\
Routine Activity & & & \\
\hline Severe Problem & $24(31.17 \%)$ & $12(18.75 \%)$ & 0.0922 \\
Non Severe & $53(68.83 \%)$ & $52(81.25 \%)$ & \\
\hline Pain & & & 0.4320 \\
$\quad$ Severe Problem & $16(20.77 \%)$ & $10(15.62 \%)$ & \\
$\quad$ Non Severe & $61(79.22 \%)$ & $54(84.38 \%)$ & \\
\hline Anxiety/Depression & & & \\
\hline Severe Problem & $25(32.47 \%)$ & $14(21.88 \%)$ & 0.1615 \\
$\quad$ Non Severe & $52(67.53 \%)$ & $50(78.12 \%)$ & \\
\end{tabular}

${ }^{*} p<0.05$, analyze with chi-square

Table 4. Evaluation of EQ-5D of patients with TBI 


\begin{tabular}{lccc}
\hline \multicolumn{1}{c}{ Parameter } & Discharged & 3 months & $p$ \\
\hline Mobility & & & \\
Severe Impairment & $26(33.77 \%)$ & $18(23.38 \%)$ & 0.1536 \\
Non Severe & $51(66.23 \%)$ & $59(76.62 \%)$ & \\
\hline Self-Care & & & \\
$\quad$ Severe Problem & $25(32.46 \%)$ & $20(25.97 \%)$ & 0.3756 \\
$\quad$ Non Severe & $52(67.53 \%)$ & $57(74.03 \%)$ & \\
\hline Routine Activity & & & \\
\hline Severe Problem & $28(36.36 \%)$ & $24(31.17 \%)$ & 0.4955 \\
Non Severe & $49(63.63 \%)$ & $53(68.83 \%)$ & \\
\hline Pain & & & 0.4463 \\
$\quad$ Severe Problem & $20(25.97 \%)$ & $16(20.77 \%)$ & \\
$\quad$ Non Severe & $57(74.03 \%)$ & $61(79.22 \%)$ & \\
\hline Anxiety/Depression & & & \\
\hline Severe Problem & $29(37.66 \%)$ & $25(32.47 \%)$ & 0.4994 \\
$\quad$ Non Severe & $48(62.34 \%)$ & $52(67.53 \%)$ &
\end{tabular}

Analyze with chi-square 